\title{
Facile one-pot synthesis of iron nanoparticles immobilized into the porous hydrochar for catalytic decomposition of phenol
}

\author{
Chao Gai ${ }^{\mathrm{a}, \mathrm{b}}$, Fang Zhang ${ }^{\mathrm{c}}$, Qianqian Lang ${ }^{\mathrm{a}, \mathrm{b}}$, Tingting Liu ${ }^{\mathrm{a}, \mathrm{b}}$, Nana Peng ${ }^{\mathrm{a}, \mathrm{b}}$, \\ Zhengang Liu ${ }^{\mathrm{a}, \mathrm{b}, *}$ \\ a Research Center for Eco-Environmental Sciences, Chinese Academy of Sciences, 18 Shuangqing Road, Beijing 100085, China \\ ${ }^{\mathrm{b}}$ University of Chinese Academy of Sciences, Beijing 100049, China \\ c Analytical and Testing Center, Beijing Institute of Technology, Beijing 100081, China
}

\section{A R T I C L E I N F O}

\section{Article history:}

Received 4 September 2016

Received in revised form

20 November 2016

Accepted 2 December 2016

Available online 7 December 2016

\section{Keywords:}

Hydrothermal carbonization

Hydrochar

Iron nanoparticles

Tar model compounds

Phenol

\begin{abstract}
A B S T R A C T
Iron-based nanocatalysts were synthesized by a green and facile one-pot hydrothermal carbonization (HTC) process. Precursory iron salts with different concentrations were dissolved together with the lignocellulosic matrix (i.e., pinewood sawdust) in the solution, and the mixtures were heated to $200{ }^{\circ} \mathrm{C}$ for $1 \mathrm{~h}$ in a sealed autoclave. After hydrothermal treatment, carbon spheres were formed with the iron precursors tightly embedded in the microsphere/mesopheres of the amorphous carbon matrix. By contrast, the impregnation of the iron salts onto the hydrothermal carbons (hydrochars) derived from HTC of sawdust were conducted as a control method. The nanomaterials prepared by these two approaches were evaluated comparatively. Compared to the impregnation approach, a nanocatalyst with more uniformly dispersed Fe nanoparticles (NPs) immobilized on the hydrochars was produced by the one-pot synthesis. Furthermore, the particle size of the Fe NPs and surface area of the nanocatalysts via the one-pot synthesis can be manipulated. The catalytic abilities of the Fe-based nanomaterials prepared by the two approaches were then tested in a fixed bed tubular reactor for biomass tar using phenol as the model compound. The nanocatalysts prepared by the one-pot synthesis exhibited higher catalytic activity in the thermal decomposition of the phenol at mild temperatures and resistance to coke deposition. The present study showed that the simple and efficient one-pot synthesis assisted uniform dispersion of Fe NPs on the surface of hydrochar through a surface-mediated chemistry. In addition, such facile one-pot synthesis may be applied to synthesize other metal or metal oxide NPs embedded in the hydrochars with more complex structures and unique chemical/physical properties.
\end{abstract}

(C) 2016 Elsevier B.V. All rights reserved.

\section{Introduction}

Exploration of biofuels or well-defined chemicals from renewable biomass rather than fossil fuels via pyrolysis/gasification is growing in recent decades. However, the formation of tar, as a thick and viscous liquid, is one of the most critical problems

Abbreviations: HTC, hydrothermal carbonization; NPs, nanoparticles; OMCVD, organometallic chemical vapor deposition; GC, gas chromatograph; TCD, thermal conductivity detector; ICP-AES, inductively coupled plasma atomic emission spectrometry; FE-SEM, field-emission scanning electron microscope; HR-TEM, high-resolution transmission electron microscopy; XRD, X-rays diffraction; BET, Brunauer-Emmet-Teller; $S_{\mathrm{BET}}$, BET surface area; $V_{\text {pore, }}$ total pore volume; TPR, emperature programmed reduction.

* Corresponding author at: Research Center for Eco-Environmental Sciences, Chinese Academy of Sciences, 18 Shuangqing Road, Beijing 100085, China.

E-mail address: zgliu@rcees.ac.cn (Z. Liu). during the pyrolysis/gasification process. Synthesis of low cost, high active, robust and coke-resistant catalysts to facilitate tar removal and improve the overall conversion efficiency is one of most urgent research topics [1-4]. In this context, various innovative synthetic methodologies of highly functionalized metal nanoparticles (NPs) has attracted considerable attention. As a benign substitute for the noble metals (e.g., Pt, Co, Pd, Ru, etc.) and their alloy NPs [5,6], nanomaterials synthesized from nonprecious and more environmentally friendly metal precursors such as iron salts have garnered special attentions [7].

The performance of supported NPs catalysts is greatly affected by the property of the supporting material in terms of pore distribution, mechanical strength, thermal and chemical stability $[8,9]$. Concerning sustainability, despite the ceaseless development of anchor metal NPs on the supports like alumina $\left(\mathrm{Al}_{2} \mathrm{O}_{3}\right)$ or silica spheres $\left(\mathrm{SiO}_{2}\right)$ by wet chemical protools (i.e., wet impregnation, sol-gel, co-precipitation, etc.) or organometallic chemical vapor 
deposition (OMCVD) [10,11], the templates of three-dimensional, benign, low toxic and inexpensive carbon-based materials (hard template) play an increasing role for the generation of metal-based nanometerials for catalysis due to the tailored porous structure and surface functional groups.

Various types of naturally abundant and low cost carbon sources have been probed as the supporting materials for the anchor of metal NPs. Yan et al. [12] reported the synthesis of carbon-encapsulated Fe NPs using pyrochar from fast pyrolysis of pine wood as the supporting material. The resultant Fe-based nanomaterial possessed a high activity for the converison of biomass-derived syngas to liquid hydrocarbons. Similarly, several groups have demonstrated that other nanostructured carbonaceous materials (e.g., activated carbon, carbon black, carbon nanotubes, graphene sheets, graphite, etc) fabricated with Fe NPs also exhibited desirable performance in the biomass transformation/conversion [13,14]. The coating of metal NPs on such carbonaceous materials is generally prepared by the surface precipitation of metal precursor to the hard templates $[9,15]$. As unsupported metal NPs are prone to agglomerate, the metalsupport interaction should be enhanced.

Biofuel production from biomass in hydrothermal media (e.g., carbonization, liquefaction, gasification) has gained increasing attention and the hydrochar prepared by the facile, inexpensive and mild hydrothermal carbonization (HTC) of the lignocellulosic biomass is another sustainable carbonaceous support for the applications of material science [16-18]. Such supports can cooperate with the metal precursor to enhance metal dispersion and promote simultaneous/mutually reactions because their surfaces are decorated with various oxygenated functional groups (e.g., hydroxyl, carboxyl, carbonyl, lactone, etc). The conventional synthesis route for metal NPs supported on the hydrochars is a multistep process that includes (i) HTC processing of pure carbohydrates/waste biomass/organic monomers, (ii) coating of hydrochars with the metal precursors, (iii) calcination. The wide-scale application of hydrochar supported NPs is limited by the tedious and complex preparation process.

In this work we demonstrated that this synthesis route can be simplified and a facile one-pot synthesis route for the preparation of Fe NPs fabricated on the hydrochars derived from a lignocellulosic matrix was proposed. The results showed that the monodispersed carbonaceous spheres with the iron precursors tightly embedded in the micro- and mesospheres were achieved by the simple one-pot synthesis.

\section{Experimental section}

\subsection{Chemicals}

Phenol (analytical pure) was purchased from Damao Chemical Reagent Factory (Tianjin, China). Iron(III) nitrate nonahydrate $\left(\mathrm{Fe}\left(\mathrm{NO}_{3}\right)_{3} \cdot 9 \mathrm{H}_{2} \mathrm{O}\right)$ was obtained from Sigma-Aldrich as the watersoluble metal precursor. All the chemicals were applied without further purification.

\subsection{Synthesis of hydrochar-supported iron catalysts}

Pinewood sawdust, a lignocellulosic matrix of the biopolymers cellulose, hemicellulose and lignin, was applied as the precursory hydrochars for the supporting materials of the Fe-based nanomaterials. The feedstock was ground and sieved to the diameter less than 100 mesh. Fe NPs were heterogeneously supported on the hydrochars of the pinewood sawdust in two protocols, as explained below. The nanomaterials prepared by the impregnation method (method A) and one-pot synthesis (method B) were labeled as
$\mathrm{Fe}_{\mathrm{x}} @ \mathrm{HC}_{\mathrm{Im}}$ and $\mathrm{Fe}_{\mathrm{x}} @ \mathrm{HC}_{\mathrm{Op}}$, respectively (where $\mathrm{x}$ was the concentration of the precursory iron salts, $\left.\mathrm{mol} \mathrm{L}^{-1}\right)$. The reaction conditions for the preparation of the iron-based nanomaterials by the two methods were illustrated in Fig. 1.

\subsubsection{Method A}

The hydrochar derived from pinewood sawdust was first produced via HTC, which was conducted on a stainless steel autoclave. A feedstock slurry of pinewood sawdust with deionized water was loaded into the reactor and kept the solid: liquid ratio of $1: 3(\mathrm{w} / \mathrm{w})$. The reactor was then sealed and heated to $200^{\circ} \mathrm{C}$ for $1 \mathrm{~h}$, and the corresponding pressure at the final reaction was $1.8 \mathrm{MPa}$. Then the reactor was rapidly cooled down to room temperature by cooling water. The hydrochar was separated from the resultant mixture by vacuum filtration and dried in an oven at $105^{\circ} \mathrm{C}$ for $12 \mathrm{~h}$.

Then the nanocomposites of Fe@HC $\mathrm{Im}$ were synthesized by an incipient wetness impregnation method. A total of $20 \mathrm{~g}$ of the hydrochar was impregnated with $100 \mathrm{ml}$ of iron nitrate solution. Several iron concentrations were applied for the Fe@HC $\mathrm{Im}$ aqueous suspensions in terms of $0.10,0.25$ and $0.50 \mathrm{~mol} \mathrm{~L}^{-1}$, which were denoted as $\mathrm{Fe}_{0.1} @ \mathrm{HC}_{\mathrm{Im}}, \mathrm{Fe}_{0.25} @ \mathrm{HC}_{\mathrm{Im}}$, and $\mathrm{Fe}_{0.5} @ \mathrm{HC}$ Im , respectively. The samples were then ultrasonicated for $40 \mathrm{~min}$ to promote uniform deposition of the iron ions into the hydrochar structure. The resulting impregnated hydrochar were then filtered by vacuum filtration and dried at $105^{\circ} \mathrm{C}$ for $24 \mathrm{~h}$. After the impregnation, the samples were calcinated in a $60 \mathrm{~mm}$ (O.D.) quartz tubular reactor at the atmospheric pressure. The iron-impregnated hydrochar were packed in the middle of the quartz tube and then heated by an electric furnace under a constant $\mathrm{N}_{2}$ (99.9\%) flowing rate of $200 \mathrm{ml} \mathrm{min}^{-1}$. After being held at $600^{\circ} \mathrm{C}$ for $1 \mathrm{~h}$, the power was turned off and the samples were cooled to ambient temperature under nitrogen atmosphere. The products were washed for several times with distilled water and ethanol, and then dried in an oven at $60^{\circ} \mathrm{C}$ for $5 \mathrm{~h}$ for further analysis.

\subsubsection{Method B}

The Fe@HC $\mathrm{Hp}_{\mathrm{Op}}$ samples were synthesized by a one-pot synthesis. Around $20 \mathrm{~g}$ of pinewood sawdust was mixed with $100 \mathrm{ml}$ of iron nitrate solutions with different concentrations. The mixture was placed in the stainless steel autoclave, sealed and then heated to $200^{\circ} \mathrm{C}$ for $1 \mathrm{~h}$ under the pressure of $1.8 \mathrm{MPa}$. The reactor was then cooled to the room temperature. The solid products were filtered off from the resultant mixture and then dried in an oven at $105^{\circ} \mathrm{C}$ for $12 \mathrm{~h}$. Then the samples were calcinated and washed under identical conditions as introduced in the method A. For comparison, the iron concentrations used during HTC were also varied from 0.10 to $0.50 \mathrm{~mol} \mathrm{~L}^{-1}$ and the nanomaterials prepared by the method $\mathrm{B}$ were denoted as $\mathrm{Fe}_{0.1} @ \mathrm{HC}_{\mathrm{Op}}, \mathrm{Fe}_{0.25} @ \mathrm{HC}_{\mathrm{Op}}$, and $\mathrm{Fe}_{0.5} @ \mathrm{HC}_{\mathrm{Op}}$, respectively.

\subsection{Catalyst evaluation}

Phenol was selected as the model compound of biomass tar. The catalytic decomposition of phenol was performed on a laboratoryscale fixed-bed quartz tubular reactor with a length of $800 \mathrm{~mm}$ and an inner diameter of $8 \mathrm{~mm}$ as reported previously [19]. The catalyst was held by quartz wool in the uniform temperature zone. In each test, $300 \mathrm{mg}$ of the catalyst was applied and the reaction temperature was kept at $600^{\circ} \mathrm{C}$. Prior to the test, nitrogen at a flow rate of $20 \mathrm{ml} \mathrm{min}^{-1}$ was fed to the reactor to keep an inert atmosphere before the quartz tube reaching the desired temperature. Phenol was vaporized at $180^{\circ} \mathrm{C}$ in a preheater and then fed into the reactor zone in the vapor state at a rate of $1.20 \mathrm{mmol} \mathrm{min}^{-1}$. The gaseous products passed through a cold gas purification unit and then the non-condensable gases were all sampled in the entire reaction time $(1 \mathrm{~h})$. The flow rate of the products was measured by a flow meter. Previous works reported that the non-condensed gases in terms of 


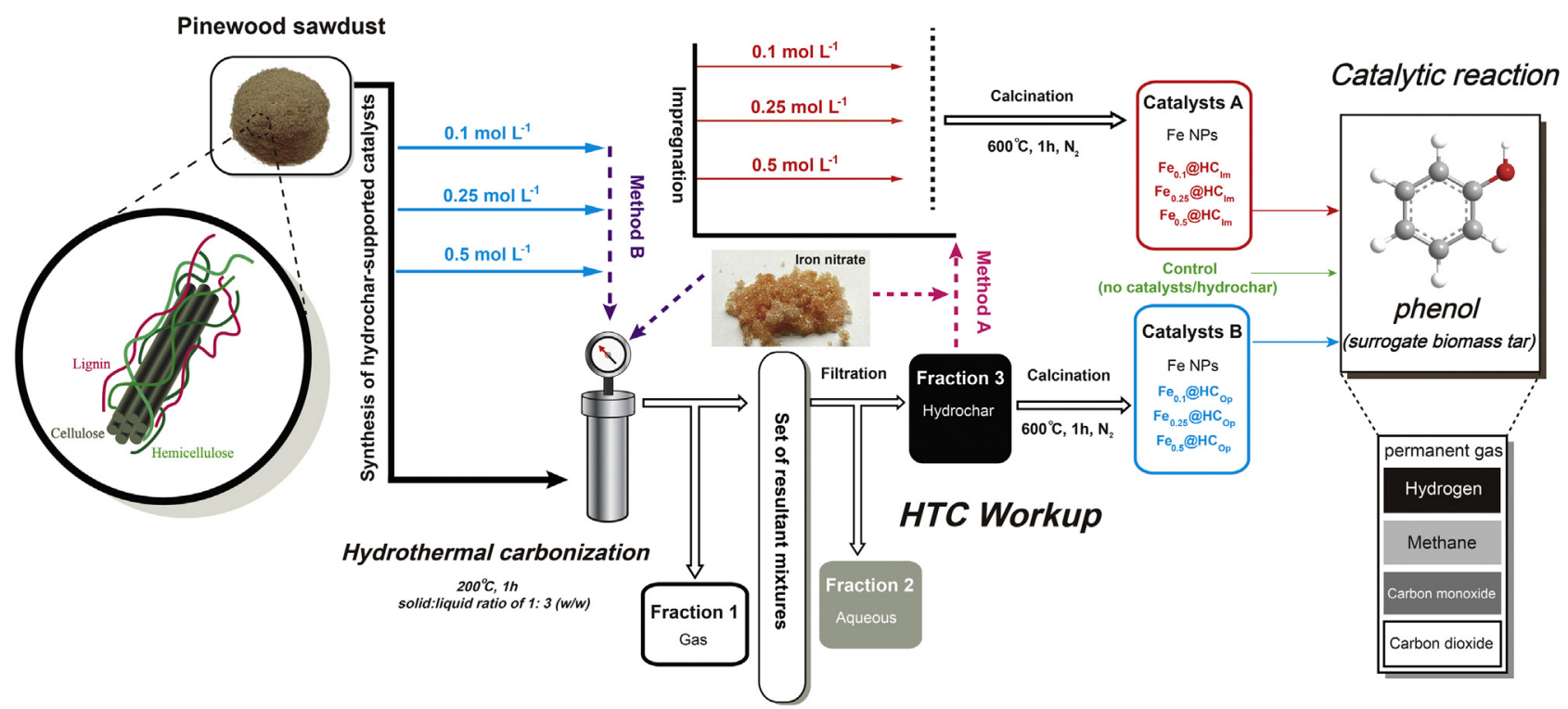

Fig. 1. Preparation conditions of iron-based nanomaterials by the impregnation approach and one-pot synthesis.

$\mathrm{H}_{2}, \mathrm{CH}_{4}, \mathrm{CO}$, and $\mathrm{CO}_{2}$ were the major gas products derived from the thermal cracking of phenol, and the intermediates are formed only to a limited extent [20]. Therefore, in this work the gaseous products (i.e., $\mathrm{CH}_{4}, \mathrm{H}_{2}, \mathrm{CO}, \mathrm{CO}_{2}$ ) were analyzed by a gas chromatograph (GC 3420A) equipped with a thermal conductivity detector (TCD) and two columns, including 5A and GDX-104. Argon was the carrier gas, and standard gas mixtures were used for quantitative calibration. Blank runs were conducted without catalyst and the pristine hydrochar as the catalyst. The conversion efficiency of phenol, $X_{\text {phenol }}$, was determined by the carbon conversion, which was calculated using the formula $\left(X_{\text {phenol }}=\left(n_{\mathrm{CO}}+n_{\mathrm{CO} 2}\right) / 6 n_{\text {phenol }} \times 100 \%\right)$, where $n_{i}$ and $n_{\text {phenol }}$ are the molar concentration of the product gas $i$ and phenol, respectively. The carbon content of the nanomaterials before and after the catalytic reaction was determined by an elemental analyzer (CE-440, Exeter Analytical Inc., North Chelmsfor, MA) and the total amount of the carbon deposited over the spent nanomaterials was determined by the mass change of the carbon before and after the reaction. The rate of deposited carbon on the surface of the spent Fe-based nanomaterials was calculated using the following formula:

$R_{d c}=\frac{M_{d c}}{M_{r c} T}$

where $R_{d c}$ is the rate of deposited carbon, $\operatorname{mg}_{c} \mathrm{~g}_{c a t}{ }^{-1} \mathrm{~h}^{-1}, M_{d c}$ is the amount of deposited carbon, $\mathrm{mg}_{C} ; M_{r c}$ is the mass of the spent catalyst, $\mathrm{g}_{\text {cat }} ; \mathrm{T}$ is the reaction time, $\mathrm{h}$.

\subsection{Characterization}

The quantities of iron loaded in the nanomaterials were determined by an inductively coupled plasma atomic emission spectrometry (ICP-AES, Leeman Prodigy, USA). The procedure involved a digestion of the sample $(0.1 \mathrm{~g})$ in a $\mathrm{HNO}_{3} / \mathrm{H}_{2} \mathrm{O}_{2} / \mathrm{HClO}_{4}$ mixture (2:2:1), and the analysis by the ICP-AES. The surface morphologies of the catalysts were observed by an HITACHI SU-8020 field-emission scanning electron microscope (FE-SEM, HITACHI, Japan) at an accelerating voltage of $5 \mathrm{kV}$. High-resolution transmission electron microscopy (HR-TEM) images were recorded using a JEOL JEM-2100 instrument (JEOL, Japan) equipped with a Gatan SC1000 ORIUS camera and operated at $200 \mathrm{kV}$. The samples were prepared by drop-casting of the dilute catalyst dispersions onto a copper grid coated with a holey carbon film. Distribution of the size of imaged particles was conducted using ImageJ software. Powder X-rays diffraction (XRD) patterns of the catalysts were recorded using a Bruker D8 Advance diffractometer (Bruker, Germany). The diffraction patterns were recorded from $10 \bigcirc$ to $80^{\circ}$ in $2 \theta$ and operated at $40 \mathrm{kV}$ and $30 \mathrm{~mA}$ with graphite monochromatic copper radiation $(\mathrm{Cu}-\mathrm{K} \alpha)$. The surface area $\left(S_{B E T}\right)$, total pore volume $\left(V_{\text {pore }}\right)$ and pore size distribution were determined by $\mathrm{N}_{2}$ adsorption-desorption isotherms employing a Micromeritics ASAP 2010 instrument (Micromeritics, USA). The samples were degassed at $150^{\circ} \mathrm{C}$ under vacuum for $8 \mathrm{~h}$ prior to the isotherms analysis. The temperature programmed reduction (TPR) with $\mathrm{H}_{2}$ was conducted with a Micrometrics ChemiSorb 2720 analyzer. A amount of $50 \mathrm{mg}$ fresh catalyst was heated under $\mathrm{He}\left(50 \mathrm{ml} \mathrm{min}^{-1}\right)$ from room temperature to $300^{\circ} \mathrm{C}$ at a rate of $10^{\circ} \mathrm{C} \mathrm{min}^{-1}$, and then kept for $60 \mathrm{~min}$. Afterwards, it was cooled to room temperature. The sample was reduced by a $5 \% \mathrm{H}_{2} / \mathrm{Ar}$ flow during an increase in temperature from room temperature to $600^{\circ} \mathrm{C}$ at a rate of $10^{\circ} \mathrm{C} \mathrm{min}^{-1}$. The consumption of $\mathrm{H}_{2}$ was monitored continuously by a thermal conductivity detector (TCD).

\section{Results and discussion}

\subsection{Iron loading}

The quantity of the Fe in the nanocatalysts prepared by two approaches was summarized in Table 1 . The Fe insertion rates for the one-pot synthesis (method B) were about two times higher than those of impregnation method. It implies that compared with the impregnation method (method A), leaching of Fe into the solvent is much low during the one-pot synthesis. This can be explained by the different mechanisms of hydrothermal carbonization of sawdust and growth of iron NPs for the two methods. The method $A$ at the atmospheric pressure may favor the formation of outersphere surface complexes, while the method B under a relatively high pressure seemed to promote the formation of inner-sphere surface complexes, which will be described further below. The significant increase in the quantity of immobilized Fe anticipates that the one-pot synthesis is more proficient in retaining the Fe NPs rather than the impregnation method. 
Table 1

Influence of the preparation methods on the quantity of Fe loaded in the hydrochars derived from pinewood sawdust.

\begin{tabular}{|c|c|c|c|c|}
\hline preparation method & {$\left[\mathrm{Fe}^{3+}\right]\left(\mathrm{mol} \mathrm{L}^{-1}\right)$} & $\begin{array}{l}\text { quantity of } \mathrm{Fe}^{3+} \text { introduced into the solution } \\
\text { per kg of precursory sawdust (mol kg } \text { sawdust }^{-1} \text { ) }\end{array}$ & $\begin{array}{l}\text { quantity of } \mathrm{Fe}^{3+} \text { loaded into the } \\
\text { precursory sawdust }\left(\mathrm{mol} \mathrm{kg}_{\text {sawdust }}{ }^{-1}\right)\end{array}$ & $\begin{array}{l}\text { rate of } \mathrm{Fe}^{3+} \text { insertion into } \\
\text { precursory sawdust (\%) }\end{array}$ \\
\hline \multirow[t]{3}{*}{ method A } & 0.1 & 0.37 & 0.149 & 41 \\
\hline & 0.25 & 0.91 & 0.305 & 33 \\
\hline & 0.5 & 1.83 & 0.562 & 31 \\
\hline \multirow[t]{3}{*}{ method B } & 0.1 & 0.5 & 0.383 & 77 \\
\hline & 0.25 & 1.25 & 0.906 & 72 \\
\hline & 0.5 & 2.50 & 1.580 & 63 \\
\hline
\end{tabular}

\subsection{Properties of the iron-based nanomaterials}

Morphologies of the Fe-based nanomaterials prepared by the two approaches were firstly studied by the FE-SEM images (Fig. 2). The presence of irregular structure was observed in all the samples, which is formed by the hydrolysis of non-saccharide components (lignin) in the pinewood sawdust. Agglomerates of micrometer sized, spherically shaped particles mixed with a large fraction of carbonaceous microspheres were also observed in all the nanomaterials. It is formed by the decomposition (e.g., dehydration, decarboxylation, depolymarization, condensation, aromatization, and nucleation) of the carbohydrates in the lignocellulosic matrix accompanied with the formation of amorphous carbon during the HTC process. Furthermore, compared to three nanocomposites prepared by the impregnation method (method A), more uniform spherical particles in the nanocomposites prepared by the onepot synthesis (method B) were observed in the FE-SEM images, which may enhance the interactions between the active sites and the reactants.

Further insights into the size and morphology of the Fe NPs were investigated by the HR-TEM micrographs. As revealed by the HR-TEM of $\mathrm{Fe}_{0.1} @ \mathrm{HC}_{\mathrm{Im}}$ and $\mathrm{Fe}_{0.1} @ \mathrm{HC}$ Op (Fig. 3), the formation of well-dispersed Fe NPs was obtained by the one-pot synthesis (method B) compared to the nanomaterials prepared by the impregnation method (method A). The uniformity was also proven by the particle size distribution of Fe NPs in the two nanomaterials shown in Fig. 3. The Fe NPs in the catalysts by the one-pot synthesis had a more uniform size and spherical shape than that in the catalysts by the impregnation method. The uniformity of the Fe NPs prepared by the one-pot synthesis was further identified by the HR-TEM characterization of $\mathrm{Fe}_{0.25} @ \mathrm{HC}_{\mathrm{Op}}, \mathrm{Fe}_{0.5} @ \mathrm{HC} \mathrm{Op}$, $\mathrm{Fe}_{0.25} @ \mathrm{HC}_{\mathrm{Im}}$, and $\mathrm{Fe}_{0.5} @ \mathrm{HC}_{\mathrm{Im}}$ (Fig. S2a-d). Better dispersion of the Fe nanoparticles could inhibit carbon deposition and is favorable to higher catalytic activity [21]. The average size of the crystallites predicted by the HR-TEM (Fig. 3) for the $\mathrm{Fe}_{0.1} @ \mathrm{HC}_{\mathrm{Op}}$ was $4.16 \mathrm{~nm}$, which was smaller than that of the $\mathrm{Fe}_{0.1} @ \mathrm{HC}_{\mathrm{Im}}(5.18 \mathrm{~nm})$. As for the catalysts by the one-pot syntheisis, smaller size of the crystallites could provide more active sites for the phenol decomposition. By contrast, the agglomeration of the Fe NPs to form bulk phase may take place for the $\mathrm{Fe}_{0.1} @ \mathrm{HC}_{\mathrm{Im}}$, because the magnetic NPs prone to aggregate due to their high surface energy and the existence of van der Waals forces [22]. Agglomeration and sintering of the Fe particles may decrease the catalytic activity. We presume that during the one-pot synthesis, hydrochars serve as stabilizing ligands for coating of the out layer of the Fe NPs to prevent the agglomeration and facilitate the formation of highly dispersed Fe NPs on the surface of the hydrochars.

The crystalline structures of the $\mathrm{Fe}_{\mathrm{x}} @ \mathrm{HC}_{\mathrm{Im}}$ and $\mathrm{Fe}_{\mathrm{x}} @ \mathrm{HC}_{\mathrm{Op}}$ were then investigated by XRD, as shown in Fig. 4. The diffraction peak at $2 \theta=43.73^{\circ}$ in the XRD patterns for all the samples are related to in-plane scattering, corresponding to the characteristic (100) plane of the graphite carbon. The graphite carbon was possibly
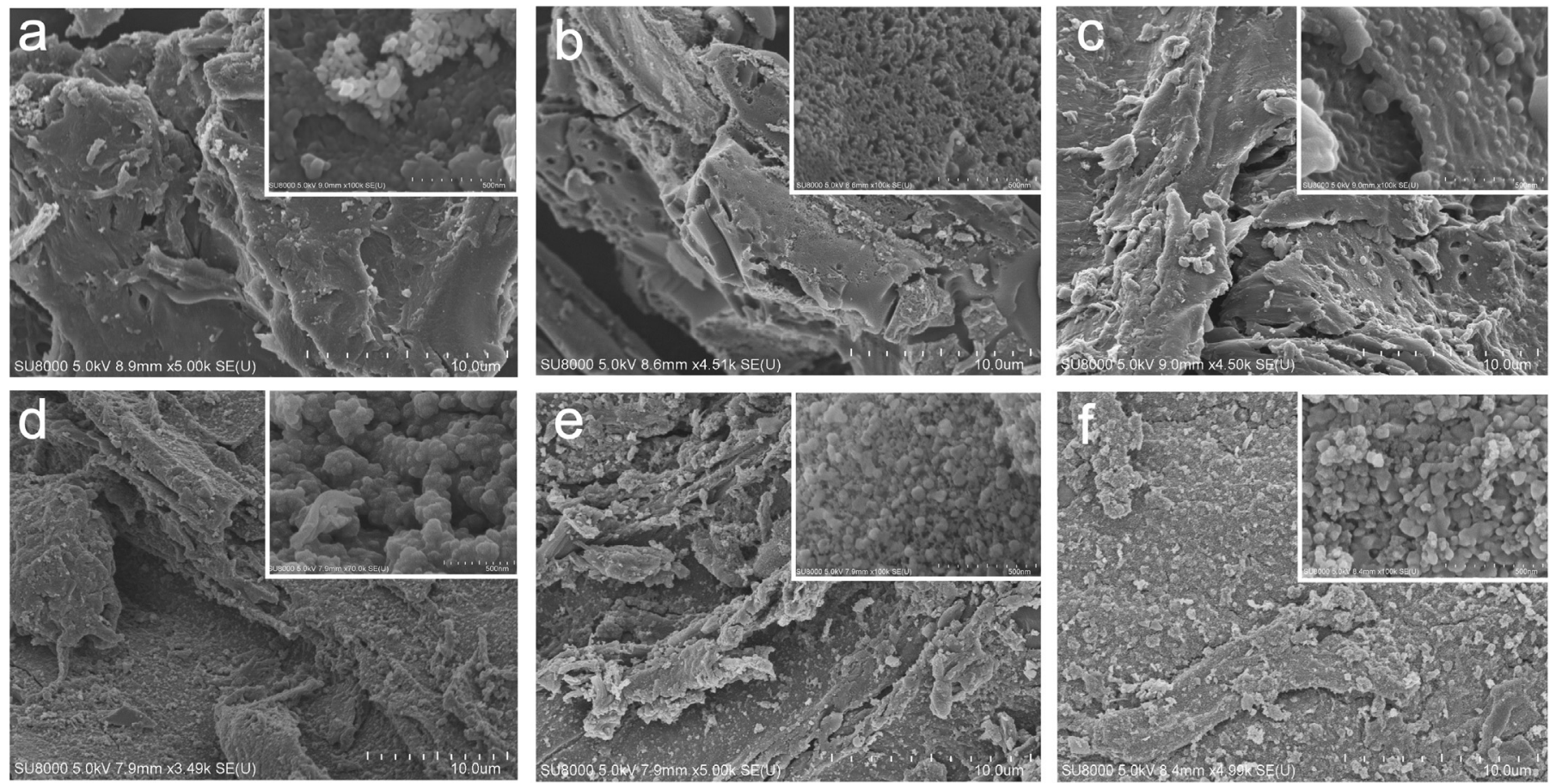

Fig. 2. FE-SEM images for catalyst $\mathrm{Fe}_{0.5} @ \mathrm{HC}_{\mathrm{Im}}(\mathrm{a}), \mathrm{Fe}_{0.25} @ \mathrm{HC} \mathrm{Im}(\mathrm{b}), \mathrm{Fe}_{0.1} @ \mathrm{HC}_{\mathrm{Im}}(\mathrm{c}), \mathrm{Fe}_{0.5} @ \mathrm{HC} \mathrm{Op}_{\mathrm{p}}(\mathrm{d}), \mathrm{Fe}_{0.25} @ \mathrm{HC}_{\mathrm{Op}}(\mathrm{e}), \mathrm{and}_{\mathrm{Fe}} \mathrm{Fe}_{0.1} @ \mathrm{HC} \mathrm{O}_{\mathrm{Op}}(\mathrm{f})$. 

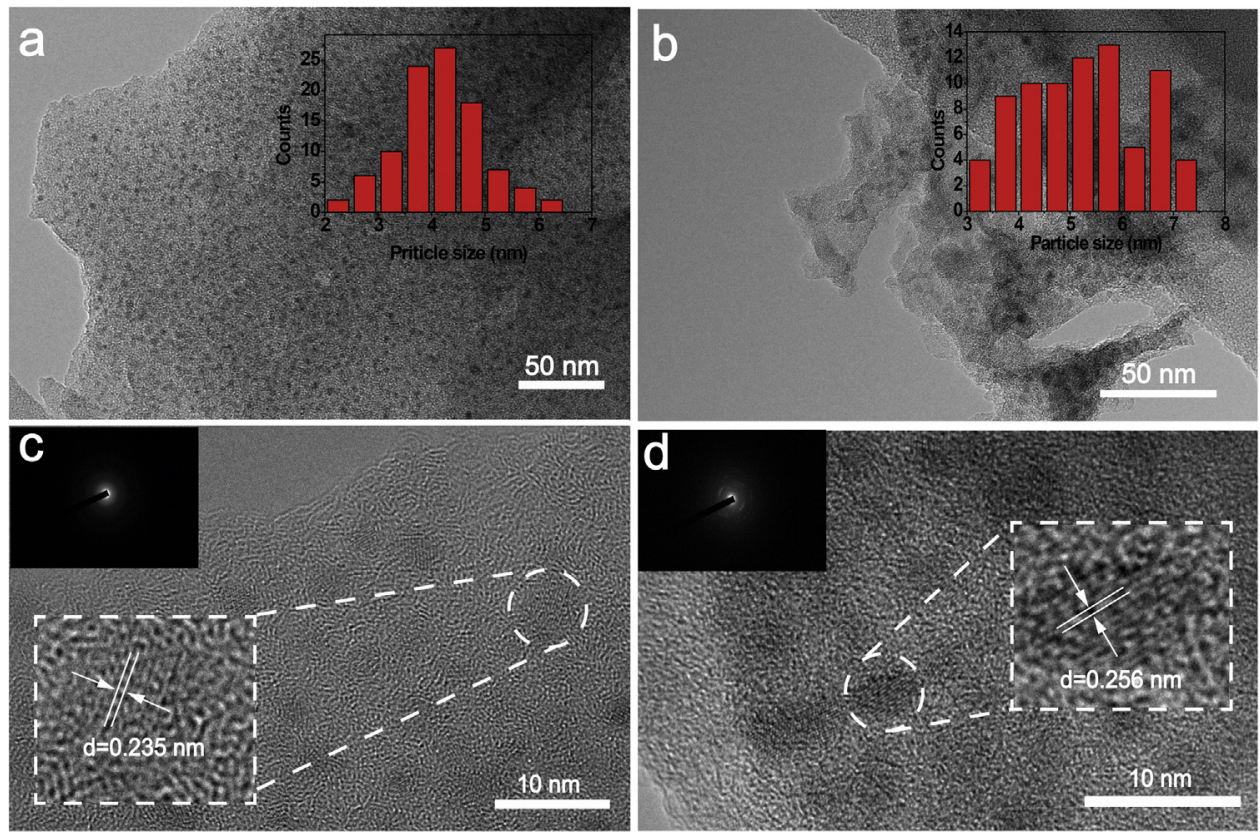

Fig. 3. HR-TEM images of $\mathrm{Fe}_{0.1} @ \mathrm{HC}_{\mathrm{Op}}(\mathrm{a}, \mathrm{c})$ and $\mathrm{Fe}_{0.1} @ \mathrm{HC} \mathrm{Im}(\mathrm{b}, \mathrm{d})$. The inset illustrates the particle size distribution of the iron nanoparticles.

formed by the catalytic graphitization of amorphous carbon by the deposited Fe NPs. As reported by Rodríguez-Manzo et al. [23], the nucleation and growth of graphene layers on the metal surfaces occurred after the amorphous carbon was taken up by the Fe crystals at temperatures around $600^{\circ} \mathrm{C}$. The energy barrier of the solid-state transformation from amorphous carbon to graphene can be lowered by the catalytically active metal, which is in accordance with this work. This peak is enhanced and became sharper for the $\mathrm{Fe}_{\mathrm{x}} @ \mathrm{HC}_{\mathrm{Op}}$ nanomaterials, implying more ordered carbon is produced via the one-pot synthesis compared to the impregnation approach. As verifed by the crystallinity index $\left(\mathrm{Cl}_{\mathrm{XRD}}\right)$ results in Table S1, the $\mathrm{Cl}_{\mathrm{XRD}}$ for the nanomaterials prepared by the one-pot synthesis is in the range of $16.1 \%-24.8 \%$, which is higher than that of the impregnation method (11.2-19.5\%) under the same concentration of the precursory iron ions. It is noteworthy to point out that the deviation of the baseline $\left(2 \theta<30^{\circ}\right)$ was observed in the XRD patterns for all the catalysts, which is attributed to the amorphous carbonaceous structure derived from HTC of the amorphous structure (e.g., hemicellulose, lignin and part of amorphous cellulose) in the lignocellulosic matrix. A less deviation of the baseline is observed for the samples of $\mathrm{Fe}_{0.25} @ \mathrm{HC}_{\mathrm{Op}}$ and $\mathrm{Fe}_{0.5} @ \mathrm{HC}_{\mathrm{Op}}$, verifying the catalytic graphitization of the amorphous carbon by the Fe NPs prepared via the one-pot synthesis.

The peaks around $30.09^{\circ}, 35.43^{\circ}, 62.54^{\circ}$, and $56.96^{\circ}$ correspond to (220), (311), (440), and (333) planes of $\mathrm{Fe}_{2} \mathrm{O}_{3}$ (PDF card: \#740748), respectively. According to Guan et al. [10], iron oxides were proficient catalysts for tar reduction. An interstitial compound of iron and carbon, iron carbide, was also observed in the XRD patterns of $\mathrm{Fe}_{\mathrm{x}} @ \mathrm{HC}_{\mathrm{Op}}$. The diffraction peaks around $42.89^{\circ}, 48.59^{\circ}$, and $54.42^{\circ}$ correspond to (211), (131), and (230) planes of $\mathrm{Fe}_{3} \mathrm{C}$ (PDF card: \#89-7271), respectively. Iron carbides can be classfied into two categories by whether the carbon atoms are located in trigonal-prismatic interstics (e.g., $\mathrm{Fe}_{5} \mathrm{C}_{2}, \mathrm{Fe}_{3} \mathrm{C}$ ) or octahedral interstices (e.g., $\mathrm{Fe}_{2} \mathrm{C}, \mathrm{Fe}_{2.2} \mathrm{C}$ ). Besides the catalysis, the forming of the carbides between carbon and iron will significantly increase the mechanical strength of the synthesied nanomaterial [24]. Furthermore, as reported by Yan et al. [12], oxygenated functionalities is effective for anchoring of metal particles and thus enhancing the thermal stability of the fabricated metal particles. We therefore infer that the iron carbide NPs prepared by the approach of one-pot
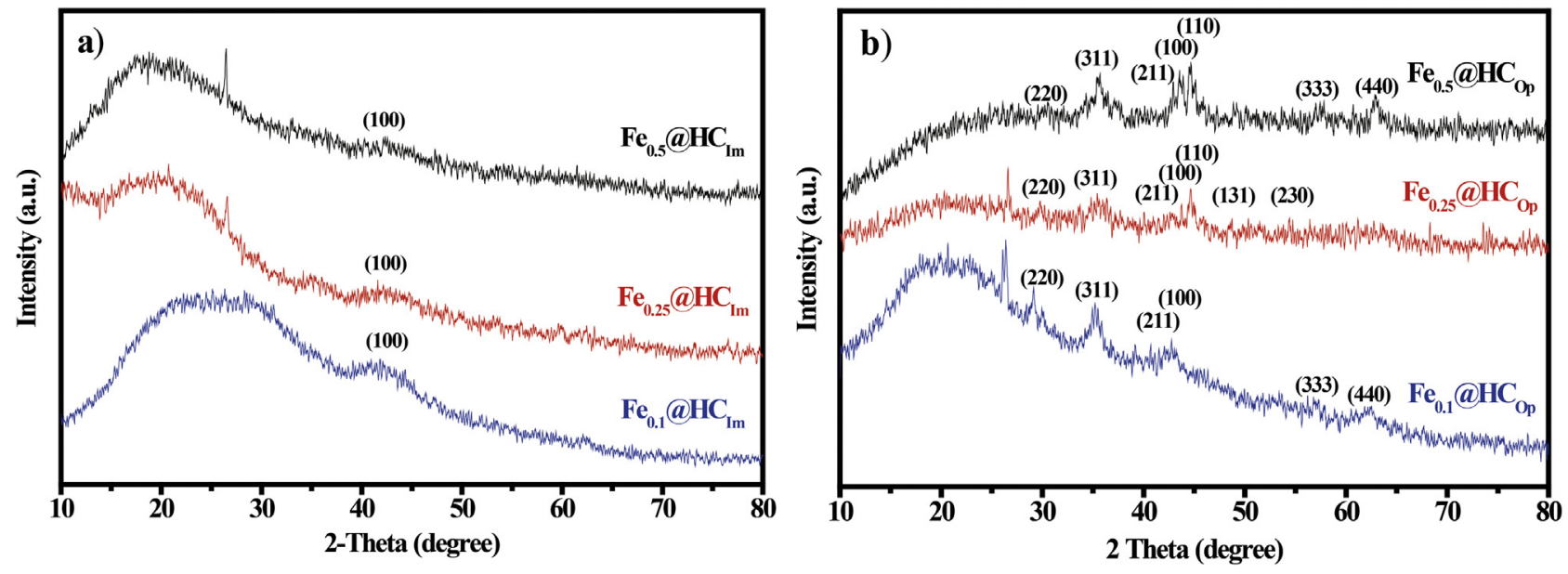

Fig. 4. XRD patterns of $\mathrm{Fe}_{\mathrm{x}} @ \mathrm{HC}_{\mathrm{Im}}(\mathrm{x}=0.1,0.25,0.5)(\mathrm{a})$ and $\mathrm{Fe}_{\mathrm{x}} @ \mathrm{HC}_{\mathrm{Op}}(\mathrm{x}=0.1,0.25,0.5)(\mathrm{b})$. 
Table 2

Surface areas and total pore volumes of the iron-based nanomaterials.

\begin{tabular}{llll}
\hline method & {$\left[\mathrm{Fe}^{3+}\right]\left(\mathrm{mol} \mathrm{L}^{-1}\right)$} & $S_{\mathrm{BET}}\left(\mathrm{m}_{2} \mathrm{~g}^{-1}\right)$ & $V_{\text {pore }}\left(\mathrm{cm}^{3} \mathrm{~g}^{-1}\right)$ \\
\hline method A & 0.1 & 446 & 0.2547 \\
& 0.25 & 794 & 0.3921 \\
& 0.5 & 401 & 0.1951 \\
method B & 0.1 & 492 & 0.2322 \\
& 0.25 & 337 & 0.1593 \\
& 0.5 & 242 & 0.1328 \\
\hline
\end{tabular}

synthesis can improve the mechanical stability of the $\mathrm{Fe}_{\mathrm{x}} @ \mathrm{HC}_{\mathrm{Op}}$ as the catalyst during the thermochemical conversion applications.

The peak at $44.67^{\circ}$ correspond to (110) lattice plane of metallic Fe (PDF card: \#87-0721). The formation of metallic Fe phase is attribited to in-situ thermal reduction of iron oxide by amorphous carbon under the processing conditions. In our recent work [25], the characteristics peak corresponding to the metallic Fe was observed when the calcination temperature was above $500^{\circ} \mathrm{C}$, which concides with this work. The combination of the iron carbide and active metallic sites by in situ reducing iron oxide appears to be ideally suited for facilitating physical processes (e.g. tar reaching the active sites of the catalyst) and chemical reactions required to convert the tar model compound to gases.

The $\mathrm{N}_{2}$ adsorption-desorption isotherms and pore size distribution of the Fe-based nanomaterials were shown in Figs. S1 and S2, respectively. The steep $\mathrm{N}_{2}$ uptakes at low relative pressure $(<0.05)$ are observed for all the samples (Fig. S1), implying the presence of micropores. The sorption isotherms for the nanomaterials prepared by two methods have different shapes at a high relative pressure. For the samples prepared by the method B, a gradual uptake at a relative pressure range from 0.45 to 1.0 is observed in the hysteresis loops, indicating the presence of mesoporous. By contrast, the hysteresis loop is not observed in the samples by the impregnation method (method A). Such hysteresis loops are mainly caused by the capillary condensation of $\mathrm{N}_{2}$ in the mesopores with wide size distributions [26-28]. As shown in Fig. S1a, the hysteresis loops are more distinct with the increased $\mathrm{Fe}^{3+}$ concentration. The result reveals that for the method $\mathrm{B}$, improving the concentration of iron ions can promote the decomposition of carbohydrates (e.g., glucose, starch, cellulose, furfural), allowing for better penetration power into the micropores and thus widening the micropores homogeneously. Magnetic NPs (e.g., metallic iron, iron oxides, and iron carbides) have been proved as proficient catalysts for hydrolysis of lignocelluloses and polysaccharides into the sugars [7,22]. As reported by $\mathrm{Hu}$ et al. [9], metal ions could effectively accelerate the HTC process of carbohydrates to form carbonaceous spheres. Therefore, Fe-based nanomaterials prepared by the impregnation method are mainly composed of micropores and diffusion limitation is expected during tar removal. However, the nanomaterials prepared by the one-pot synthesis can produce a hydrochar with more mesopores, which allows for the rapid and easy diffusion of the reactants during the catalytic processes. Pore size distributions of the catalysts (Fig. S2) agree well with this observation. Nevertheless, the Fe-based nanocatalysts derived from the hydrochar are still rich of micropores, although the catalysts by the one-pot synthesis contain more mesopores than that of the catalysts from the impregnation method.

Further quantitative analysis for the surface area $\left(S_{\mathrm{BET}}\right)$ and the total pore volume $\left(V_{\text {pore }}\right)$ of the nanocomposites of $\mathrm{Fe}_{\mathrm{x}} @ \mathrm{HC}_{\mathrm{Im}}$ and $\mathrm{Fe}_{\mathrm{x}} @ \mathrm{HC}_{\mathrm{Op}}$ were summarized in Table 2. Notably, the apparent surface area of the prepraed composites is highly dependent on the preparation method and $\mathrm{Fe}^{3+}$ concentration. At lower $\mathrm{Fe}^{3+}$ concentration $\left(0.1 \mathrm{~mol} \mathrm{~L}^{-1}\right)$, no significant difference in $S_{\mathrm{BET}}$ is found between the $\mathrm{Fe}_{0.1} @ \mathrm{HC}_{\mathrm{Op}}\left(492 \mathrm{~m}^{2} \mathrm{~g}^{-1}\right)$ and $\mathrm{Fe}_{0.1} @ \mathrm{HC}_{\mathrm{Op}}$ $\left(446 \mathrm{~m}^{2} \mathrm{~g}^{-1}\right)$. However, the catalyst of $\mathrm{Fe}_{0.25} @ \mathrm{HC}_{\mathrm{Op}}\left(337 \mathrm{~m}^{2} \mathrm{~g}^{-1}\right)$

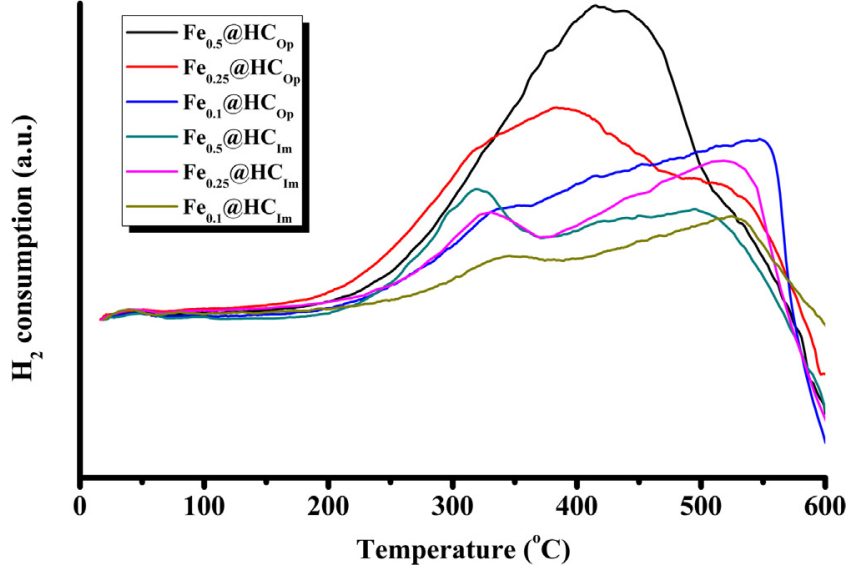

Fig. 5. $\mathrm{H}_{2}$-TPR images of catalyst $\mathrm{Fe}_{0.5} @ \mathrm{HC}_{\mathrm{Im}}(\mathrm{a}), \mathrm{Fe}_{0.25} @ \mathrm{HC} \mathrm{Im}(\mathrm{b}), \mathrm{Fe}_{0.1} @ \mathrm{HC}_{\mathrm{Imd}}$ (c), $\mathrm{Fe}_{0.5} @ \mathrm{HC}_{\mathrm{Op}}(\mathrm{d}), \mathrm{Fe}_{0.25} @ \mathrm{HC}_{\mathrm{Op}}(\mathrm{e})$, and $\mathrm{Fe}_{0.1} @ \mathrm{HC}_{\mathrm{Op}}$ (f).

and $\mathrm{Fe}_{0.5} @ \mathrm{HC}_{\mathrm{Op}}\left(242 \mathrm{~m}^{2} \mathrm{~g}^{-1}\right)$ with a highly graphitic structure (as revealed by the XRD patterns in Fig. 4) possesses a lower BET surface area compared to $\mathrm{Fe}_{0.25} @ \mathrm{HC}_{\mathrm{Im}}\left(794 \mathrm{~m}^{2} \mathrm{~g}^{-1}\right)$ and $\mathrm{Fe}_{0.5} @ \mathrm{HC}_{\mathrm{Im}}$ $\left(401 \mathrm{~m}^{2} \mathrm{~g}^{-1}\right)$. Furthermore, the surface area of the nanomaterials produced by the one-pot synthesis can be manipulated by varying the concentration of iron salts, as can be seen for the three samples prepared from different concentrations. The surface area decreased markedly from $492 \mathrm{~m}^{2} \mathrm{~g}^{-1}$ of $\mathrm{Fe}_{0.1} @ \mathrm{HC}_{\mathrm{Op}}$ to $242 \mathrm{~m}^{2} \mathrm{~g}^{-1}$ of $\mathrm{Fe}_{0.5} @ \mathrm{HC}_{\mathrm{Op}}$ when the $\mathrm{Fe}^{3+}$ concentration was increased from 0.1 to $0.5 \mathrm{~mol} \mathrm{~L}^{-1}$. This can be explained to the blockage of pores induced by increased Fe species loaded into the pore channels and the collapse of the well-defined microporous structure due to the catalytic graphitization of amorphous carbon by the increased $\mathrm{Fe}^{3+}$ concentration [29], which coincides with the XRD patterns (Fig. 4). Together with the HR-TEM results (Fig. 3), the results reveal that compared with the impregnation method, the one-pot synthesis contributes to a better penetration of the active metal component into the larger pores (i.e., mesopores observed in Fig. S1) of the hydrochar, resulting in a well-dispersed Fe NPs within hydrochar.

The reducibility of the catalysts prepared by the two approaches was studied by $\mathrm{H}_{2}$-TPR analysis, and the profiles were shown in Fig. 5. The TPR profile of the three $\mathrm{Fe}_{\mathrm{x}} @ \mathrm{HC}_{\mathrm{Im}}$ catalysts prepared by the impregnation method have two reduction centers while the three $\mathrm{Fe}_{\mathrm{x}} @ \mathrm{HC}_{\mathrm{Op}}$ catalysts prepared by one-pot synthesis exhibit only a single reduction peak. The low-temperature reduction peak at around $320-340^{\circ} \mathrm{C}$ for the three $\mathrm{Fe}_{\mathrm{x}} @ \mathrm{HC} \mathrm{C}_{\mathrm{Im}}$ catalysts imply the presence of uninteracted Fe species because unsupported Fe species are easily reduced by $\mathrm{H}_{2}$ at temperatures below $400^{\circ} \mathrm{C}$ $[7,30]$. No such reduction center was observed on the TPR profile of the $\mathrm{Fe}_{\mathrm{x}} @ \mathrm{HC}_{\mathrm{Op}}$ catalysts, indicating a strong metal-support interactions for the catalysts prepared by one-pot synthesis. The reduction peak at around $400-500{ }^{\circ} \mathrm{C}$ for the $\mathrm{Fe}_{\mathrm{x}} @ \mathrm{HC}_{\mathrm{Op}}$ catalysts and the second reduction center for the $\mathrm{Fe}_{\mathrm{x}} @ \mathrm{HC} \mathrm{C}_{\mathrm{Im}}$ catalysts correspond to the reduction of Fe species to metallic iron $[31,32]$. The reduction peaks of the catalysts of $\mathrm{Fe}_{0.25} @ \mathrm{HC}_{\mathrm{Op}}\left(390^{\circ} \mathrm{C}\right)$ and $\mathrm{Fe}_{0.5} @ \mathrm{HC}_{\mathrm{Op}}\left(413^{\circ} \mathrm{C}\right)$ are located at lower reduction temperature range than that of the catalysts of $\mathrm{Fe}_{0.5} @ \mathrm{HC}_{\mathrm{Im}}\left(497^{\circ} \mathrm{C}\right), \mathrm{Fe}_{0.25} @ \mathrm{HC}_{\mathrm{Im}}\left(522^{\circ} \mathrm{C}\right)$ and $\mathrm{Fe}_{0.1} @ \mathrm{HC} \mathrm{Im}$ $\left(527^{\circ} \mathrm{C}\right)$. This suggests that the catalysts prepared by the one-pot synthesis have higher reducibility. Overall, $\mathrm{H}_{2}$-TPR analysis showed that the one-pot synthesis promoted the formation of Fe species which had a strong interaction with the carbonaceous support compared with the impregnation approach. 


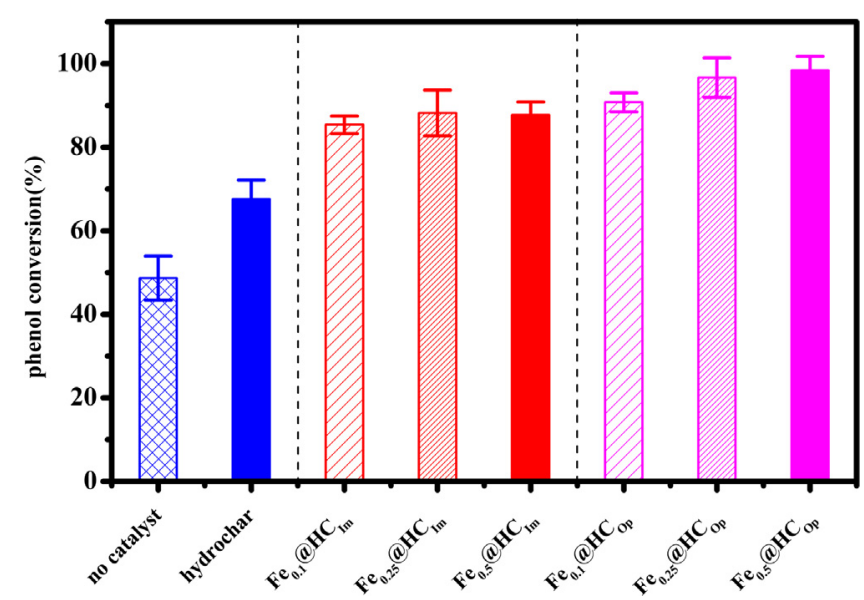

Fig. 6. Phenol conversion rates with iron-based nanomaterials prepared by the two approaches.

\subsection{Catalytic activity and selectivity}

Efficient catalytic decomposition of the biomass tar to small molecules is still challenged by the complex compositions of the tar. The main components of the biomass tar are phenolic, alkylated aromatic and polycyclic aromatic hydrocarbons, many of those including phenolic (e.g., phenol, cresols) and alkylated aromatic compounds (e.g., toluene, xylene, styrene), are challenged to be thermally decomposed under mild temperature [33]. Many of the studies of tar reduction were conducted with model compounds such as phenol [34], toluene [35], and benzene [36]. In this work, we used phenol as the model compound of biomass tar to explore the catalytic performance of the $\mathrm{Fe}_{\mathrm{x}} @ \mathrm{HC}_{\mathrm{Im}}$ and $\mathrm{Fe}_{\mathrm{x}} @ \mathrm{HC}_{\mathrm{Op}}$ catalysts prepared by these two methods. This is because phenolic compounds mirror the most persistent and abundant components in the biomass tar [1,37], which are mainly derived from the demethoxylation of the phenylpropane units (e.g., guaiacol/2methoxyphenol) of the macromolecular lattice of lignin in the lignocellulosic matrix [38]. For blank runs, we also tested the thermal decomposition of phenol under the same condition with no catalyst and using the pristine hydrochar as the catalyst.

Fig. 6 showed the conversion efficiency of the phenol from the catalytic tests. As expected, a $67.6 \%$ conversion rate of phenol was obtained for the hydrochar, which was much higher than that of the control test with no catalyst (48.7\%). A remarkably high conversion of phenol was observed for the Fe-based nanomaterials, and the samples prepared by the one-pot synthesis exhibited more superior catalytic performance (90.7-98.4\%) than the catalysts synthesized by the impregnation method (85.4-87.7\%). Although the catalyst prepared by the impregnation method has high BET surface area compared to that of one-pot synthesis under the same concentration of $\mathrm{Fe}^{3+}$ (see Table 2), the Fe NPs prepared by the latter approach exhibits higher catalytic activity for the phenol decomposition. As reported previously, the intrinsic activity of the Fe-based catalyst is more related to the phase than to the surface area. It was reported that the activity of iron catalyst remained almost constant for particie sizes larger than $6 \mathrm{~nm}[39,40]$. Iron carbide nanostructure exhibited excellent catalytic activity for energy conversion [13,41-43]. In this study, the iron carbide NPs synthesized by the one-pot synthesis (see the XRD patterns shown in Fig. 4) may contribute to the enhanced catalytic activity for the phenol decomposition. Another reason for this difference is that the catalyst prepared by the one-pot synthesis resulted in a higher iron loading on the hydrochar in comparison with the impregnation method (as shown in Table 1).

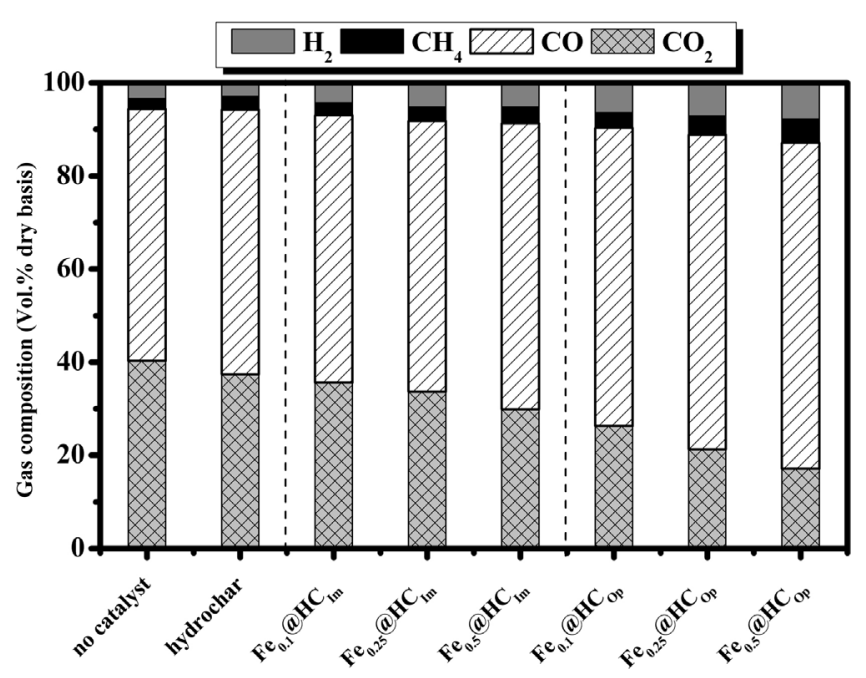

Fig. 7. Selectivity of the main gas products from the catalytic decomposition of phenol.

Fig. 7 depicted the selectivity of the main gas compositions obtained from the catalytic decomposition of phenol by the Febased nanomaterials. One can see that the main gaseous products are $\mathrm{CO}$ and $\mathrm{CO}_{2}$. Interestingly, the resulting $\mathrm{Fe}_{\mathrm{x}} @ \mathrm{HC}$ op catalysts exhibited higher selectively catalytic for $\mathrm{H}_{2}$ and $\mathrm{CO}$. The selectivities of $\mathrm{H}_{2}$ and $\mathrm{CO}$ continuously increased from 3.3\% and $64 \%$ by $\mathrm{Fe}_{0.1} @ \mathrm{HC}_{\mathrm{Op}}$ to $7.8 \%$ and $70 \%$ by $\mathrm{Fe}_{0.5} @ \mathrm{HC}_{\mathrm{Op}}$, respectively. The above results revealed that the fabrication of Fe NPs on the hydrochar by one-pot synthesis have higher catalytic activity for the thermal cracking of phenol as biomass tar model compared to the impregnation method. The characterizations of the spent catalysts will clarify these results. Shen et al. [44], investigated the catalytic reforming of biomass tar over metallic nickel nanoparticles embedded in the pyrochar of rice husk and a great reforming efficiency of $99.8 \%$ for tar. It is verified that the biochar derived from HTC or pyrolysis can both be used as a desirable carbonaceous support for tar removal [45]. Taking into account of the difference in preparation method and physicochemical properties of the products, the comparison of the catalytic performance between the hydrochar and pyrochar as the catalyst for tar reduction is recommended for further study.

\subsection{Characterization of the spent catalysts}

During the tar reforming process, carbon deposition on the catalyst will poison the active sites, block the pores of the support and render catalyst deactivation, which should be paid special attention during the development of an industrial catalyst for pilot-scale biomass gasification $[46,47]$. In this work, the rate of deposited carbon on the surface of the spent iron-based nanomaterials was calculated and the results were summarized in Table 3. All the coke deposition rates of the six nanocatalysts were substantially lower

Table 3

Carbon deposition rates of the spent iron-based nanomaterials. ${ }^{\mathrm{a}}$

\begin{tabular}{ll}
\hline catalyst & rate of carbon deposition $\left(\mathrm{mg}_{\mathrm{C}} \mathrm{g}_{\mathrm{cat}}{ }^{-1} \mathrm{~h}^{-1}\right)$ \\
\hline Hydrochar & 19.7 \\
$\mathrm{Fe}_{0.1} @ \mathrm{HC}$ & 7.8 \\
$\mathrm{Fe}_{0.25} @ \mathrm{HC}_{\mathrm{Im}}$ & 5.9 \\
$\mathrm{Fe}_{0.5} @ \mathrm{HC} C_{\mathrm{Im}}$ & 5.2 \\
$\mathrm{Fe}_{0.1} @ \mathrm{HC}$ Op & 3.5 \\
$\mathrm{Fe}_{0.25} @ \mathrm{HC}$ & 2.2 \\
$\mathrm{Fe}_{0.5} @ \mathrm{HC}$ & 1.2 \\
\hline
\end{tabular}

a Reaction conditions: reaction temperature $=600^{\circ} \mathrm{C}$; reaction time $=1 \mathrm{~h}$; phe$\mathrm{nol}=1.202 \mathrm{mmol} \mathrm{min}^{-1} ; \mathrm{W}=300 \mathrm{mg}$. 

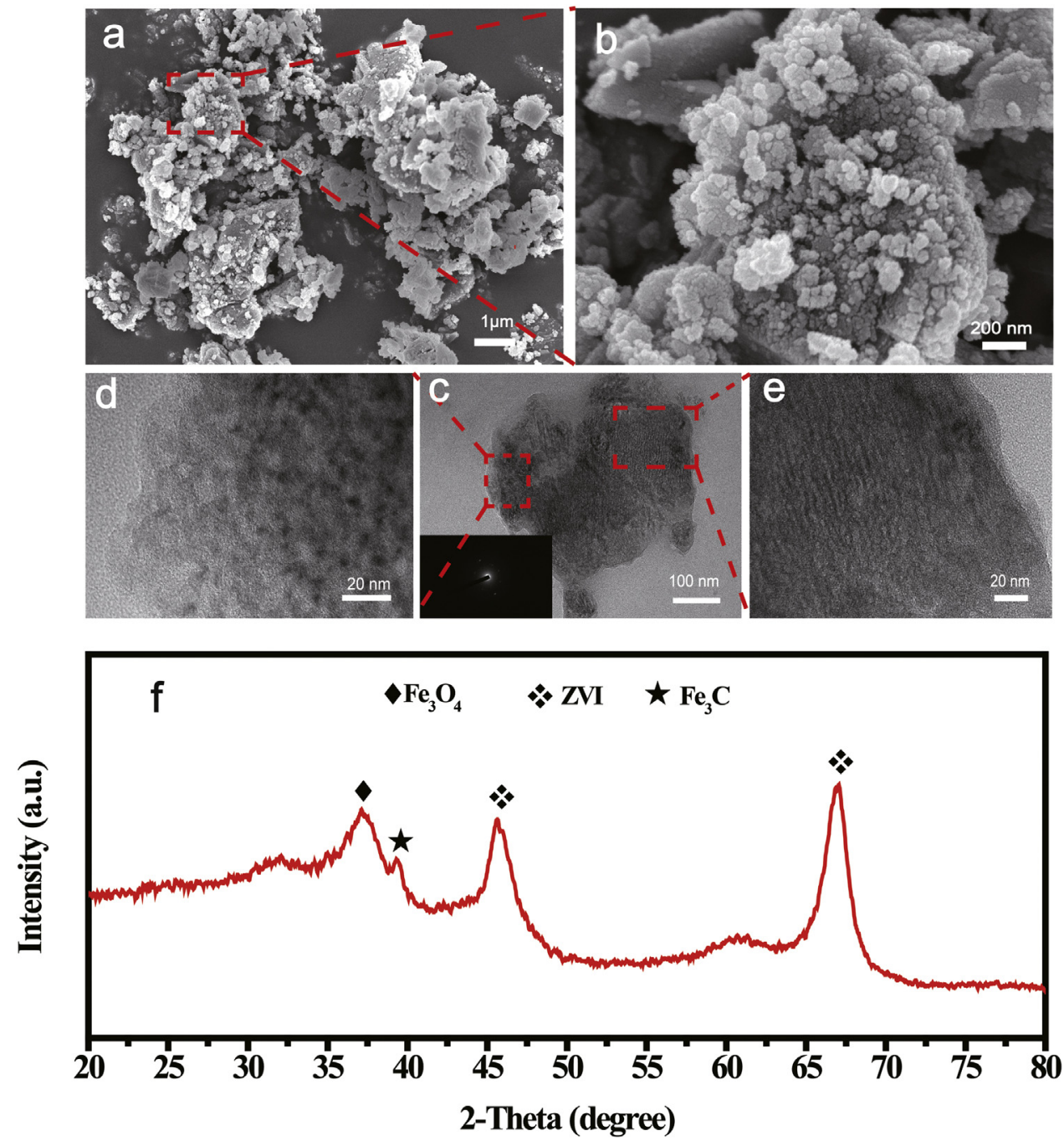

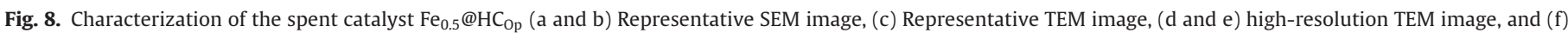
XRD patterns.

than that of pristine hydrochar $\left(19.7 \mathrm{mg}_{\mathrm{C}} \mathrm{g}_{\mathrm{cat}}{ }^{-1} \mathrm{~h}^{-1}\right)$ and no apparent morphology change of the Fe-based catalysts was observed after the catalytic reaction, as shown by SEM image of the spent catalyst $\mathrm{Fe}_{0.5} @ \mathrm{HC}_{\mathrm{Op}}$ (Fig. 8a,b) and other catalysts (Fig. S4). In addtion, the carbon deposition rates for the nanomaterials prepared by the one-pot synthesis $\left(1.2-3.5 \mathrm{mg}_{\mathrm{C}} \mathrm{g}_{\mathrm{cat}}{ }^{-1} \mathrm{~h}^{-1}\right)$ were lower than those of the impregnation method $\left(5.2-7.8 \mathrm{mg}_{\mathrm{C}} \mathrm{g}_{\mathrm{cat}}{ }^{-1} \mathrm{~h}^{-1}\right)$. The relatively high carbon deposition rate for the nanomaterials prepared by the impregnation method may account for its relatively lower catalytic efficiency because the deposited carbon can encapsulate the active metal components, decreasing the number of active metal sites. Lower reducibility of the catalysts prepared by the impregnation method result in the catalyst deactivation, which is verified by $\mathrm{H}_{2}-$ TPR analysis. The carbon deposition was reported to result from growth of metal particles during tar reduction $[48,49]$. Further insights into the morphology and structure of the catalysts after the tests were obtained by FESEM observations (Figs. $8 \mathrm{c}-\mathrm{e}$ and S5). It was found that Fe nanoparticles after the catalytic reaction were still well dispersed on the catalysts prepared by the one-pot synthesis (Figs. 8 c-e, and S5a,b) and the particle size of Fe nanoparticles was almost constant during the catalytic reaction. However, the presence of a large particle size for the catalysts prepared by the impregnation method (Fig. S5c-e) implied the sintering of Fe nanoparticles during the catalytic reaction. As revealed by $\mathrm{H}_{2}-\mathrm{TPR}$ analysis (Fig. 5), the strong Fe-support interaction for the catalysts by one-pot synthesis makes it difficult for the deposited carbon to lift the Fe NPs from the support during the reaction process. As for the catalysts by the impregnation method, some Fe nanoparticles could not be restrained by the pore channels of the hydrochar due to the weak interaction between Fe NPs and the carbonaceous support. These Fe nanoparticles may be detached from the support by the carbon species, moved from the internal channels to the external surface of the porous hydrochar and then were probably agglomerated under harsh catalytic conditions. Therefore, it was verified that the $\mathrm{Fe}_{\mathrm{x}} @ \mathrm{HC}_{\mathrm{Op}}$ catalysts prepared by one-pot synthesis exhibited better suppression of the metal agglomeration and improved stability during the reaction. These properties are associated with their high catalytic activity for the phenol decomposition.

The participation of Fe nanoparticles during catalytic conversion were further studied by wide-angle XRD patterns. For the spent catalyst of $\mathrm{Fe}_{0.5} @ \mathrm{HC}_{\mathrm{Op}}$, the diffraction peaks $2 \theta=45.72^{\circ}$ and $66.95^{\circ}$ corresponding to metallic iron was observed on the XRD patterns of the spent $\mathrm{Fe}_{0.5} @ \mathrm{HC}_{\mathrm{Op}}$ (Fig. 8f), suggesting that part of the iron oxides are converted to metallic iron during the reaction. The phase of $\mathrm{Fe}_{3} \mathrm{O}_{4}$ was observed in the XRD patterns of the spent catalyts (Figs. $8 \mathrm{f}$ and S6), corresponding to the reduction of $\mathrm{Fe}_{2} \mathrm{O}_{3}$ to $\mathrm{Fe}_{3} \mathrm{O}_{4}$ during the reaction. However, no $\mathrm{Fe}^{0}$ phase was observed in the XRD patterns of the other five catalysts. It is likely that for the 


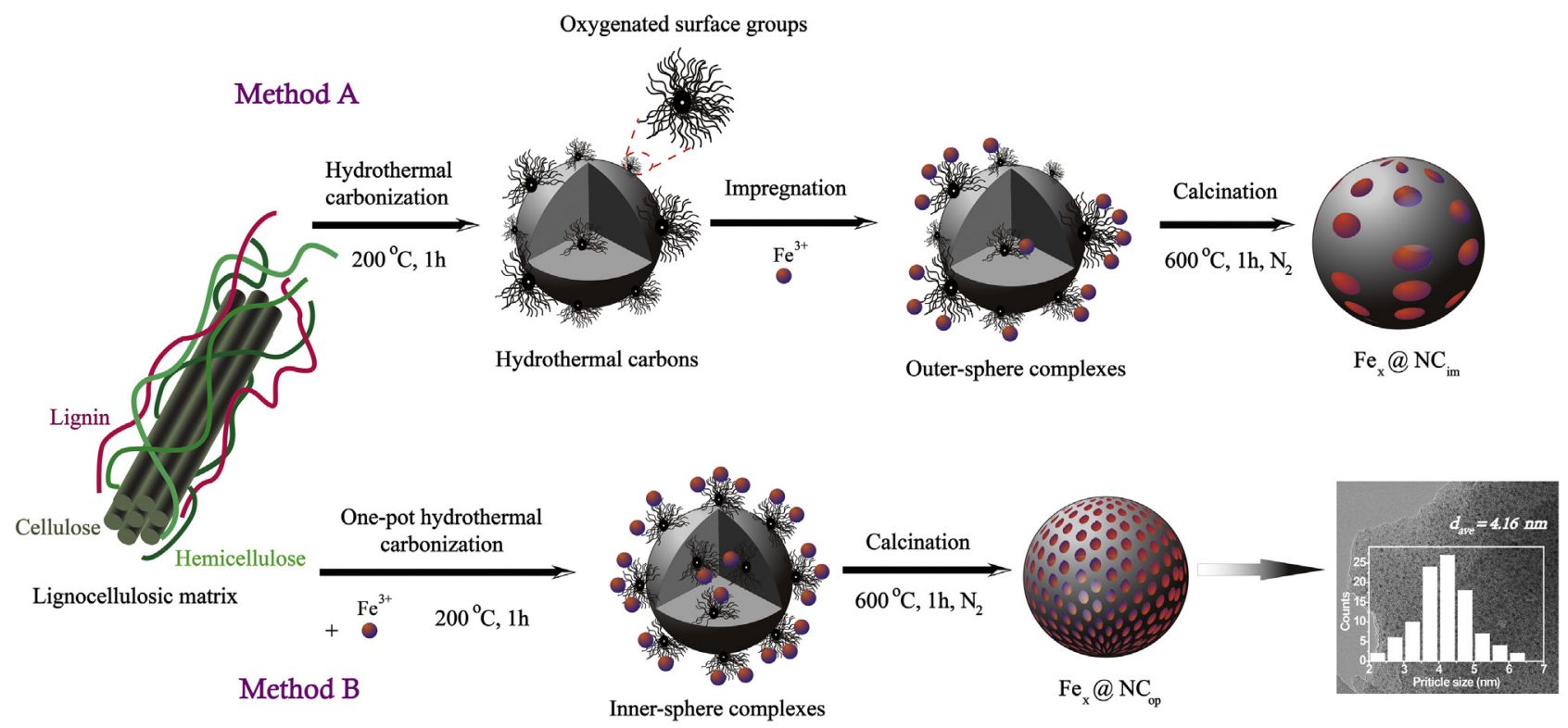

Fig. 9. Schematic illustration of the synthesis of iron nanoparticles supported on hydrochars from HTC of lignocellulosic matrix.

spent $\mathrm{Fe}_{0.5} @ \mathrm{HC}_{\mathrm{Op}}$, most iron oxide phases are located at the outer surface layer but the iron in the inner layer is largely metallic. The sub-surface reduction of $\mathrm{Fe}_{2} \mathrm{O}_{3}$ to and $\mathrm{Fe}^{0}$ for the $\mathrm{Fe}_{0.5} @ \mathrm{HC}_{\mathrm{Op}}$ and the surface reduction of $\mathrm{Fe}_{2} \mathrm{O}_{3}$ to $\mathrm{Fe}_{3} \mathrm{O}_{4}$ for the other five catalysts imply that for the catalyst of $\mathrm{Fe}_{0.5} @ \mathrm{HC}_{\mathrm{Op}}$, the Fe species incorporated the pore channels of the carbonaceous support is available for the reactants during the catalytic reaction. According to Guan et al. [10], although the iron oxide like $\mathrm{Fe}_{2} \mathrm{O}_{3}$ could act as the catalyst for the decomposition of biomass tar, the catalytic activity could be enhanced when the Fe NPs are in the metallic state. Therefore, it is anticipated that the catalyst of $\mathrm{Fe}_{0.5} @ \mathrm{HC}_{\mathrm{Op}}$ prepared by the onepot synthesis enable the iron particles inside the support available for the reactants during the catalytic reaction, thus exhibited the highest catalytic activity for the phenol decomposition compared to other five catalysts (Fig. 6). HR-TEM image of the spent catalyst $\mathrm{Fe}_{0.5} @ \mathrm{HC}_{\mathrm{Op}}$ (Fig. 8e) clearly showed cylindrical-shaped pore channel, and the channels were uniform. Such channels were not observed in other spent catalysts (Fig. S5). This observation verified the speculation, and it was in good agreement with the XRD analysis.

\subsection{Mechanistic interpretation}

The formation and growth of hydrochars via the HTC process were generally proposed by the core-shell LaMer model [50], which was composed of a hydrophobic core and a hydrophilic shell. A high content of oxygen was retained in the inner part of the hydrochar particles during HTC process due to the formation of stable oxygen groups (e.g., ether, pyrone, quinone, etc) in the hydrophobic core [18], while the surface of the hydrochar is hydrophilic with a distribution of $-\mathrm{OH}$ and $-\mathrm{C}=\mathrm{O}$ functionalities. Based on LaMer mechanism, Vreeland et al. [51], proposed a general model for fine size control during the synthesis of nanoparticles, especially for magnetite nanoparticles (i.e., $\mathrm{Fe}_{3} \mathrm{O}_{4}$ ). In this work, we demonstrate that the particle size of the Fe NPs can be manipulated by varying the concentration of the precursory iron ions during the one-pot synthesis (as revealed by the XRD patterns in Fig. 4). Furthermore, we presume that different carbonization and growth mechanisms exist for the one-pot synthesis (method $B$ ) under relative high pressure compared with the impregnation approach (method A) in atmospheric pressure. Fig. 9 proposed a schematic illustration of the effect of two preparation methods on the type of interactions between the $\mathrm{Fe}^{3+}$ cations and the hydrochars derived from the lignocellulosic matrix.

In the HTC process, numerous oxygenated functionalities (e.g., hydroxyl, carboxylic, phenolic, carbonyl, etc.) were formed on the hydrophilic shell of the hydrochar, which was verified by previous studies [52,53]. These functionalities serve as the adsorption sites for the iron cations in aqueous solution, facilitating better dispersion of the precursory iron salts within the hydrochar. As a result, the carbon-Fe precursor interaction can be enhanced during the impregnation of the precursory iron ions into the hydrochar from the HTC process. Generally, the adsorption of iron ions on hydrophilic oxygenated functional groups are dominated by two pathways: (i) electrostatic attraction, and (ii) dispersion in terms of hydrogen bonding, $\pi-\pi$ interactions, and electron donor-acceptor interactions. The impregnation method (method A) at the atmospheric pressure may favor the electrostatic attraction with the outer hydration shell of the $\mathrm{Fe}^{3+}$ cations or the formation of hydrogen bonds between the water molecules and the hydrophilic functional groups, leading to the formation of outer-sphere surface complexes.

By contrast, the one-pot synthesis (method $\mathrm{B}$ ) under a relative high pressure (i.e., 1.8 MPa) may provide suitable conditions for the formation of inner-sphere surface complexes. Hydrolysis reactions proceed at the early stages of the HTC process. Cellulose, one of the major components of the lignocellulosic matrix, is hydrolyzed to glucose and different oligomers in terms of cellobiose, cellotriose, cellohexaose, cellotetraose, and cellopentaose [54]. The oligomers are further hydrolyzed to respective monomers and then undergo further decomposition (e.g., $\mathrm{C}-\mathrm{C}$ bond breaking or ring opening) to the formation of different aldehydes including acetonylacetone, acetaldehyde, pyruvaldehyde, glyceraldehyde, and glycolaldehyde [55]. Aldehydes may also be derived from the decomposition of the furfural compounds. Then induced by the intermolecular dehydration and aldol condensation, aromatization and nucleation reaction take place. Less reactive oxygenated groups will be formed in the hydrophobic core of the carbon spheres while the reactive oxygencontaining functional groups (e.g. hydroxyl, carboxylic, carbonyl, etc) are linked on the out layer of the carbon spheres. During the one-pot synthesis, the iron salts can be in situ reduced by the aldehyde groups of the carbohydrates in the hydrochar, leading to the 
formation of metallic Fe NPs. This reduction may proceed prior to the intermolecular dehydration and aldol condensation during the HTC process, thus affecting the subsequent aromatization and nucleation reactions. Furthermore, as the Fe NPs are hydrophobic, they will be preferentially in-situ dispersed in the hydrophobic core of the hydrochar, resulting in the formation of inner-sphere surface complexes. Therefore, it is expected that during the one-pot synthesis, agglomerates of the Fe NPs are predominantly located near the hydrophobic core of the carbon spheres, and this difference in outer-sphere and inner-sphere pathways provides a plausible explanation for the more uniformly dispersed Fe NPs immobilized on the hydrochars prepared by the one-pot synthesis and better catalytic ability for the decomposition of phenol.

\section{Conclusions}

The fabrication of Fe NPs on the mesopore-rich hydrochar by a simple and facile one-pot synthesis was developed. By the HTC of mixtures of pinewood sawdust and precursory iron salts, the carbon spheres with the Fe NPs homogenesously doped on the hydrophilic shell as amorphous clusters were formed. Compared to the conventional impregnation of iron ions onto the hydrochar, the one-pot synthesis facilitated uniformly dispersed Fe NPs supported on the hydrochars and the concentration of iron ions was crucial to control the morphology and particle size of the Fe NPs. The Febased nanocatalysts obtained by one-pot synthesis exhibited better resistantce against agglomeration of Fe nanoparticles and higher coke resistance than the conventional impregnation method, which contribute to their higher catalytic activities and stabilities in the thermal decomposition of phenol at mild temperatures. These ironbased nanomaterials offer promising potential for the biomass tar reduction, and future work will be directed toward the catalytic behavior of real tar from the biomass gasification process.

\section{Acknowledgements}

The authors gratefully acknowledge financial support for Zhengang Liu from the " 100 Talents" Program of the Chinese Academy of Sciences (Project No. 121311ZXPP2014002), State Natural Sciences Fund (Project No. 3190021501405), Beijing Natural Science Foundation (Project No. 8164064), Opening Project of Key Laboratory for Solid Waste Management and Environment Safety in Tsinghua University (Project No. SWMES 2015-13), and Key Laboratory of Solid Waste Treatment and Resource Recycle in Southwest University of Science and Technology (Project No. 15zxgk01).

\section{Appendix A. Supplementary data}

Supplementary data associated with this article can be found, in the online version, at http://dx.doi.org/10.1016/j.apcatb.2016. 12.005 .

\section{References}

[1] M. Virginie, J. Adánez, C. Courson, L.F. de Diego, F. García-Labiano, D. Niznansky, A. Kiennemann, P. Gayan, A. Abad, Effect of Fe-olivine on the tar content during biomass gasification in a dual fluidized bed, Appl. Catal. B-Environ. 121-122 (2012) 214-222.

[2] Y. Richardson, J. Motuzas, A. Julbe, G. Volle, J. Blin, Catalytic investigation of in situ generated Ni metal nanoparticles for tar conversion during biomass pyrolysis, J. Phys. Chem. C 117 (2013) 23812-23831.

[3] Y. Shen, P. Zhao, Q. Shao, D. Ma, F. Takahashi, K. Yoshikawa, In-situ catalytic conversion of tar using rice husk char-supported nickel-iron catalysts for biomass pyrolysis/gasificaiton, Appl. Catal. B-Environ. 152-153 (2014) $140-151$.

[4] P.H. Blanco, C. Wu, J.A. Onwudili, P.T. Williams, Characterization and evaluation of $\mathrm{Ni} / \mathrm{SiO}_{2}$ catalysts for hydrogen production and tar reduction from catalytic steam pyrolysis-reforming of refuse derived fuel, Appl. Catal. B-Environ. 134-135 (2013) 238-250.
[5] Y. Richardson, J. Blin, G. Volle, J. Motuzas, A. Julbe, In situ generation of Ni metal nanoparticles as catalyst for $\mathrm{H}_{2}$-rich syngas production from biomass gasification, Appl. Catal. A-Gen. 382 (2010) 220-230.

[6] P.M. Mortensen, J.D. Grunwaldt, P.A. Jensen, A.D. Jensen, Screening of catalysts for hydrodeoxygenation of phenol as a model compound for bio-oil, ACS Catal. 3 (2013) 1774-1785.

[7] L. Harivardhan Reddy, J.L. Arias, J. Nicolas, P. Couvreur, Magnetic nanoparticles: design and characterization, toxicity and biocompatibilit, pharmaceutical and biomedical applications, Chem. Rev. 112 (2012) 5818-5878.

[8] H. Kim, N.J. Jeong, S.O. Han, Synthesis of a catalytic support from natural cellulose fibers and its performance in a $\mathrm{CO}_{2}$ reforming of $\mathrm{CH}_{4}$, Appl. Catal. B-Environ. 113-114 (2012) 116-125.

[9] B. Hu, K. Wang, L. Wu, S.H. Yu, M. Antonietti, M.M. Titirici, Engineering carbon materials from the hydrothermal carbonization process of biomass, Adv. Mater. 22 (2010) 1-16.

[10] G. Guan, G. Chen, Y. Kasai, E.W.C. Lim, X. Hao, M. Kaewpanha, A. Abuliti, C. Fushimi, A. Tsutsumi, Catalytic steam reforming of biomass tar over iron- or nickel-based catalyst supported on calcined scallop shell, Appl. Catal. B-Environ. 115-116 (2012) 159-168.

[11] J. Ashok, Y. Kathiraser, M.L. Ang, S. Kawi, Ni and/or Ni-Cu alloys supported over $\mathrm{SiO}_{2}$ catalysts synthesized via phyllosilicate structures for steam reforming of biomass tar reduction, Catal. Sci. Technol. 5 (2015) 4398-4409.

[12] Q. Yan, C. Wan, J. Liu, J. Gao, F. Yu, J. Zhang, Z. Cai, Iron nanoparticles in situ encapsulated in biochar-based carbon as an effective catalyst for the conversion of biomass-derived syngas to liquid hydrocarbons, Green Chem. 15 (2013) 1631-1640.

[13] K. Bazaka, M.V. Jacob, K. Ostrikov, Sustainable life cycles of natural-precursor-derived nanocarbons, Chem. Rev. 116 (2016) 163-214.

[14] M.M. Titirici, M. Antonietti, Chemistry and materials options of sustainable carbon materials made by hydrothermal carbonization, Chem. Soc. Rev. 39 (2010) 103-116.

[15] F. Chen, C. Wu, L. Dong, A. Vassallo, P.T. Williams, J. Huang, Characteristics and catalytic properties of $\mathrm{Ni} / \mathrm{CaAlO}_{\mathrm{x}}$ catalyst for hydrogen-enriched syngas production from pyrolysis-steam reforming of biomass sawdust, Appl. Catal. B-Environ. 183 (2016) 168-175.

[16] T.H. Pedersen, L.A. Rosendahl, Production of fuel range oxygenates by supercritical hydrothermal liquefaction of lignocellulosic model systems, Biomass Bioenergy 83 (2015) 206-215.

[17] L. Garcia Alba, C. Torri, D. Fabbri, S.R.A. Kersten, D.W.F. Brilman, Microalgae growth on the aqueous phase from hydrothermal liquefaction of the same microalgae, Chem. Eng. J. 228 (2013) 214-223.

[18] M. Sevilla, A.B. Fuertes, The production of carbon materials by hydrothermal carbonization of cellulose, Carbon 47 (2009) 2281-2289.

[19] C. Gai, Y. Guo, T. Liu, N. Peng, Z. Liu, Hydrogne-rich gas production by steam gasification of hydrochar derived from sewage sludge, Int. J. Hydrogen Energy 41 (2016) 3363-3372.

[20] D. Fuentes-Cano, A. Gómez-Barea, S. Nilsson, P. Ollero, Decompostion kinetics of model tar compounds over chars with different internal structure to mode hot tar removal in biomass gasificaiton, Chem. Eng. J. 228 (2013) 1223-1233.

[21] N. Wang, K. Shen, L. Huang, X. Yu, W. Qian, W. Chu, Facile route for synthesizing ordered mesoporous $\mathrm{Ni}$-Ce-Al oxide materials and their catalytic performance for methane dry reforming to hydrogen and syngas, ACS Catal. 3 (2013) 1638-1651

[22] B. Liu, Z. Zhang, Catalytic conversion of biomass into chemicals and fuels over magnetic catalysts, ACS Catal. 6 (2016) 326-338.

[23] J.A. Rodríguez-Manzo, C. Pham-Huu, F. Banhart, Graphene growth by a metal-catalyzed solid-state transformation of amorphous carbon, ACS Nano 5 (2011) 1529-1534.

[24] N.N. Greenwood, A. Earnshaw, Chemistry of the Elements, Pergamon, Oxford, UK, 1984, pp. 318.

[25] Z. Liu, F. Zhang, S.K. Hoekman, T. Liu, C. Gai, N. Peng, Homogeneously dispersed zerovalent iron nanopaticles supported on hydrochar-derived porous carbon: simple, in situ synthesis and use for dechlorination of PCBs, ACS Sustain. Chem. Eng. 4 (2016) 3261-3267.

[26] J. Tang, R.R. alunkhe, J. Liu, N.L. Torad, M. Imura, S. Furukawa, Y. Yamauchi, Thermal conversion of core-shell metal-organic frameworks: a new method for selectively functionalized nanoporous hybrid carbon, J. Am. Chem. Soc. 137 (2015) 1572-1580.

[27] C. Gérardin, J. Reboul, M. Bonne, B. Lebeau, Ecodesign of ordered mesoporous silica materials, Chem. Soc. Rev. 42 (2013) 4217-4255.

[28] X. Ma, X. Wang, C. Song, Molecular basket sorbents for separation of $\mathrm{CO}_{2}$ and $\mathrm{H}_{2} \mathrm{~S}$ from various gas streams, J. Am. Chem. Soc. 131 (2009) 5777-5783.

[29] A.M. Schwenke, S. Hoeppener, U.S. Schubert, Synthesis and modification of carbon nanomaterials utilizing microwave heating, Adv. Mater. 27 (2015) 4113-4141.

[30] H. Wan, B. Wu, H. Xiang, Y. Li, Fischer-Tropsch synthesis: influence of support incorporation manner on metal dispersion metal-support interaction, and activities of iron catalysts, ACS Catal. 2 (2012) 1877-1883.

[31] I. Zamboni, C. Courson, A. Kiennemann, Fe-Ca interactions in Fe-based/CaO catalyst/sorbent for $\mathrm{CO} 2$ sorption and hydrogen production from toluene steam reforming, Appl. Catal. B-Environ. 203 (2017) 154-165.

[32] J. Ashok, S. Kawi, Nickel-Iron alloy supported over Iron-Alumina catalysts for steam reforming of biomass tar model compound, ACS Catal. 4 (2014) 289-301. 
[33] A.M. Fraind, J.D. Tovar, Comparative survey of conducting polymers containing benzene, naphthalene, and anthracene cores: interplay of localized aromaticity and polymer electronic structures, J. Phys. Chem. B 114 (2010) 3104-3116.

[34] B. Matas Guell, I.V. Babich, L. Lefferts, K. Seshan, Steam reforming of phenol over Ni-based catalysts-A comparative study, Appl. Catal. B-Environ. 106 (2011) 280-286.

[35] D. Swierczyński, S. Libs, C. Courson, A. Kiennemann, Steam reforming of tar from a biomass gasification process over Ni/olivine catalyst using toluene as a model compound, Appl. Catal. B-Environ. 74 (2007) 211-222.

[36] Y.N. Chun, S.C. Kim, K. Yoshikawa, Removal characteristics of tar benzene using the externally oscillated plasma reformer, Chem. Eng. Process. 57-58 (2012) 65-74.

[37] A. Kruse, A. Funke, M.M. Titirici, Hydrothermal conversion of biomass to fuels and energetic materials, Curr. Opin. Chem. Biol. 17 (2013) 515-521.

[38] M. Stöcker, Biofuels and biomass-to-liquid fuels in the biorefinery: catalytic conversion of lignocellulosic biomas using porous materials, Angew. Chem. Int. Ed. 47 (2008) 9200-9211.

[39] C. Yang, H. Zhao, Y. Hou, D. Ma, $\mathrm{Fe}_{5} \mathrm{C}_{2}$ nanoparticles: a facile bromide-induced synthesis and as an active phase for Fischer-Tropsch synthesis, J. Am. Chem. Soc. 134 (2012) 15814-15821.

[40] E.de Smit, B.M. Weckhuysenn, The renaissance of iron-based Fischer-Tropsch synthesis: on the multifaceted catalyst deactivation hehavirour, Chem. Soc. Rev. 37 (2008) 2758-2781.

[41] V. Georgakilas, J.N. Tiwari, K. Christian Kemp, J.A. Perman, A.B. Bourlinos, K.S Kim, R. Zboril, Noncovalent functionalization of graphene and graphene oxide for energy materials biosensing, catalytic, and biomedical applications, Chem. Rev. 116 (2016) 5464-5519.

[42] C. Giordano, A. Kraupner, I. Fleischer, C. Henrich, G. Klingelhöfer, M. Antonietti, Non-conventional $\mathrm{Fe}_{3} \mathrm{C}$-based nanostructures, J. Mater. Chem. 21 (2011) 16963-16967.

[43] A. Meffre, B. Mehdaoui, V. Kelsen, P.F. Fazzini, J. Carrey, S. Lachaize, M. Respaud, B. Chaudret, A simple chemical route toward monodisperse iron carbide nanoparticles displaying tunable magnetic and unprecedented hyperthermia properties, Nano Lett. 12 (2012) 4722-4728.
[44] Y. Shen, M. Chen, T. Sun, J. Jia, Catalytic reforming of pyrolysis tar over metallic nickel nanoparticles embedded in pyrochar, Fuel 159 (2015) 570-579.

[45] Y. Shen, J. Wang, X. Ge, M. Chen, By-products recycling for syngas cleanup in biomass pyrolysis-An overview, Renew. Sust. Energ. Rev. 59 (2016) 1246-1268.

[46] P.H. Moud, K.J. Andersson, R. Lanza, K. Engvall, Equilibrium potassium coverage and its effect on a Ni tar reforming catalyst in alkali- and sulfur-laden biomass gasification, Appl. Catal. B-Environ. 190 (2016) 137-146.

[47] L. Devi, K.J. Ptasinski, F.J.J.G. Janssen, A review of the primary measures for tar elimination in biomass gasification processes, Biomass Bioenergy 24 (2003) $125-140$.

[48] C. Wu, L. Wang, P.T. Williams, J. Shi, J. Huang, Hydrogen production from biomass gasification with Ni/MCM-41 catalysts: influence of Ni content, Appl. Catal. B-Environ. 108-109 (2011) 6-13.

[49] P.R. Buchireddy, R.M. Bricka, J. Rodriguez, W. Holmes, Biomass gasification: catalytic removal of tars over zeolites and Nickel supported zeolites, Energy Fuel 24 (2010) 2707-2715.

[50] V.K. Lamer, R.H. Dinegar, Theory, production and mechanism of formation of monodispersed hydrosols, J. Am. Chem. Soc. 72 (1950) 4827-4854.

[51] E.C. Vreel, J. Watt, G.B. Schober, B.G. Hance, M.J. Austin, A.D. Price, B.D Fellows, T.C. Monson, N.S. Hudak, L. Maldonad-Camargo, A.C. Bohorquez, C. Rinaldi, D.L. Huber, Enhanced nanoparticle size control by extending LaMer's mechanism, Chem. Mater. 27 (2015) 6059-6066.

[52] C. Gai, Y. Guo, N. Peng, T. Liu, Z. Liu, N-doped biochar derived from co-hydrothermal carbonization of rice husk and chlorella pyrenoidosa for enhancing copper ion adsorption, RSC Adv. 6 (2016) 53713-53722.

[53] C. Gai, M. Chen, T. Liu, N. Peng, Z. Liu, Gasification characteristics of hydrochar and pyrochar derived from sewage sludge, Energy 113 (2016) 957-965.

[54] Y. Ogihara, J.R.L. Smith, H. Inomate, K. Arai, Direct observation of cellulose dissolution in subcritical and supercritical water over a wide range of water densities (550-1000 kg/m³), Cellulose 12 (2005) 595-606.

[55] J.N. Chheda, G.W. Huber, J.A. Dumesic, Liquid-phase catalytic processing of biomass-derived oxygenated hydrocarbons to fuels and chemicals, Angew. Chem. Int. Ed. 46 (2007) 7146-7183 